\title{
MARXISMO Y DERECHO: SOBRE LA CRÍTICA DE POULANTZAS A PASHUKANIS Y STUCHKA
}

\section{Cristóbal Ramos Guerrero ${ }^{1}$}

\section{Resumen:}

El propósito de esta exposición es considerar parte de las reflexiones críticas de Nicos Poulantzas acerca del derecho, en el periodo donde su obra fue más influenciada por el pensamiento de Louis Althusser. Para esto, centraré mi análisis ocupando algunas de las ideas planteadas en los artículos La teoría marxista del Estado y del derecho y el problema de la alternativa y Marx y el derecho moderno, en conjunto con obras más extensas como Poder político y clases sociales en el estado capitalista y Fascismo y dictadura, en la cual podemos comenzar a considerar que se ha alejado de la médula del proyecto althusseriano, en el cual el derecho es parte constitutiva de la totalidad social, en tanto instancia de la superestructura. Dentro de este análisis, abordaré las distintas críticas que realiza a autores soviéticos como Pashukanis y Stuchka, buscando una posible respuesta a la luz de lo que plantean estos autores en sus respectivas obras, con la finalidad de develar posibles limitaciones de lo que plantea Poulantzas, su incapacidad para analizar una formación económico-social concreta, y finalmente sus dificultades para la construcción de hegemonía.

Palabras clave: Estado; Derecho ;Poder ; Hegemonía

\section{LA CARACTERIZACIÓN DE POULANTZAS}

Como sabemos, las fuentes del pensamiento de Poulantzas no son coincidentes con las que inspiran las ideas de Marx, como explica Bob Jessop, éstas son: la filosofía francesa, la política italiana, y el derecho romano-germánico. La primera fuente es la que determina la periodificación habitual de la obra poulantziana, atendiendo a las tres concepciones de la filosofía que influenciaron determinantemente su producción teórica, las cuales son el existencialismo sartriano, el althusserianismo, y la microfísica del poder foucaultiana ${ }^{2}$. Con todo, a pesar de las diferencias conceptuales entre los distintos periodos, respecto al derecho las reflexiones de Poulantzas no variarán demasiado, al menos en dos aspectos:

1. La principal materialización del derecho, la ley, presenta los siguientes caracteres dentro del modo de producción capitalista, a saber:

\footnotetext{
${ }^{1}$ Estudiante de derecho en la Universidade de Chile. E-mail: toba.ramos@gmail.com

${ }^{2}$ Dentro de este período la obra más significativa es, sin duda alguna, L'Etat, le pouvoir, le socialisme Hay traducción en español Estado, poder y socialismo.Madrid, Siglo XXI, 1979.
} 
a) Abstracción, los conceptos utilizados por el derecho son construidos a partir de realidades de las que formamos parte y no al revés. Ejemplos de estas abstracciones son las nociones de personalidad, sujeto de derecho, contrato, etc. Se opone esta característica a la idea de lo "concreto".

b) Generalidad, el hecho de que la regla general sea que las normas sean aplicables a cualquier persona, no previendo mayores casos particulares. Esta aplicabilidad no se agota en un caso concreto, sino que subsiste mientras exista un interés de que la norma sea aplicada de manera indefinida. Se opone esta característica tanto a "lo particular" como a "lo individual". La relevancia de esta propiedad para Poulantzas radica en que viene a limitar los efectos del atributo anterior; luego, una norma de derecho no puede ser absolutamente abstracta. A pesar de que no conozcamos la extensión de ciertos conceptos o nociones, entendemos que la abstracción misma subsiste por su aplicabilidad en casos comunes, el ejemplo dado por Poulantzas es uno del derecho romano: las reglas respecto a los derechos reales presentarían más bien un carácter general aunque el mismo concepto abstracto de "derechos reales" no estuviera completamente definido"

c) Formalismo, que consiste en que las reglas, valores y normas jurídicas, se presentan como desposeídas de contenido concreto. Se opone esta característica a la noción de "materialidad". La distinción entre formalidad y abstracción, que al común de la gente puede sonarle a ratos incomprensible, para los operadores del derecho no lo es, como lo explica Karl Engisch (a quien cita Poulantzas para explicar esta dimensión de ámbito de lo jurídico), puesto que éstos conviven a diario con la formalidad como un atributo de la abstracción. Así, los operadores del derecho se encuentran con ideas como la antijuridicidad formal en el derecho penal, la verdad formal en el derecho procesal, sin que estos sean meras ideas abstractas. ${ }^{4}$

d) La reglamentación de las normas, que es siempre estricta.

2. Estas características siempre se subordinan a la necesidad de prever la actividad del hombre. O, en palabras del autor, "es precisamente esta necesidad la que está en la base de un intento de fijación de los valores jurídicos, de su conservación en el tiempo, del establecimiento de su duración”.5. Estas son las características que explicarían la lógica interna del derecho, mas la última proposición deja la puerta abierta a la pregunta siguiente ¿qué pone en su lugar a las normas jurídicas imperantes ${ }^{6}$ ? Según Poulantzas, para darle respuesta a

\footnotetext{
${ }^{3} \ll(\ldots)$ les règles concernant les droits réels présentaient bien un caractère général alors que le concept abstrait même de «droit réels» n'était point définitivement établi » POULANTZAS, Nicos. Nature des choses et droit: essai sur la dialectique. Paris, Librairie générale de droit et de jurisprudence, 1965, págs. 262-263

${ }^{4}$ Existe traducción al español. ENGISCH, Karl. La idea de concreción en el derecho. Pamplona, Ediciones Universidad de Navarra, 1968.

${ }^{5} \ll(\ldots)$ c'est précisément ce besoin qui est à la base d'une tentative de fixation de valeurs juridiques, de leur conservation dans le temps, d'établissement de leur durée » Poulantzas, op. cit. pág. 236.

${ }^{6}$ En este punto, tanto Bob Jessop, como Luiz Eduardo Motta, intentando mostrar distintas cosas en sus ensayos, coinciden en que es una aplicación del método dialéctico interno-externo para desarrollar las contradicciones que se muestran manifiestas en el derecho. JESSOP, Bob. Nicos Poulantzas. Marxist Theory and Political Strategy. Londres, Macmillan, 1985, p. 40; vol.07, nº. 02, Rio de Janeiro, 2014. pp. 469-481 
esta pregunta, resulta necesario hacer un análisis diacrónico de la totalidad a la cual se agregan y/o eliminan normas jurídicas. Así, sólo analizando los factores cuyo movimiento influye en el devenir de la sociedad en uno u otro sentido, podremos comenzar a mostrar cómo el derecho comienza a desplegarse y a diferenciarse de los otros órdenes normativos. Estos factores serían los siguientes:

a) La movilidad del orden [jurídico], que resulta apto para prever y asegurar sus propias transformaciones;

b) El inicio de una sistematización según los dictados de la lógica formal, respondiendo a las características de abstracción, generalidad y formalidad, abre la puerta a la reversibilidad de las instituciones de derecho positivo. Esta sistematización tiene una doble función: por un lado, parece indispensable para una eficiente existencia de reglas de cambio; por el otro, excluye toda otra modificación fundamental para la transformación total de la estructura del conjunto del sistema?

Lo que resulta interesante de todo esto es que antes de la pregunta respecto a la causa de la validez de la normas en última instancia, no existe una ruptura radical con respecto a la concepción positivista clásica del derecho. Es más, el análisis hecho por el positivismo es reafirmado, puesto que no sería incompatible el estudio de la lógica interna del derecho (aunque sin incluir una grundnorm en el sentido de Kelsen) con los elementos de análisis que nos entregaría la tradición marxista. Así, por ejemplo, Poulantzas considerará que su diferencia con Kelsen es metodológica, ya que éste no sigue un método dialéctico interno-externo como el que el griego plantea, estribando aquí la diferencia fundamental: si bien el derecho se encuentra vinculado con el estado, ambos no son dos caras de la misma moneda (que es para Kelsen, la organización de la fuerza), sino que el estado, en su estructura misma, tiene una extensión que aunque le permite abarcar al derecho como abstracción, impide a éste explicarlo como un todo estructurado, con participación en la base ni en la superestructura.

MOTTA, Luiz Eduardo, "Direito, estado e poder: Poulantzas e o seu confronto com Kelsen”. Revista de Sociologia e Política. Vol. 19. $\mathrm{N}^{\circ} 38, \mathrm{pp} .7-25$.

${ }^{7}$ En este análisis es evidente la incipiente influencia del pensamiento de Althusser en la primera etapa creadora de Poulantzas, como reconocerá después en el prefacio a la selección de artículos editadas por el grupo Pasado y Presente en 1967 (me refiero a POULANTZAS, Nicos. Hegemonía y dominación en el Estado Moderno. Córdoba, Ediciones Pasado y Presente, 1969). Así también, como afirma James Martin, Poulantzas comenzará poco a poco a cambiar la centralidad del derecho como tema de estudio para pasar al estudio del Estado, en el modo de producción capitalista. MARTIN, James. The Poulantzas Reader. Londres, Verso, 2008.

El desarrollo de la respuesta en la tesis doctoral de Poulantzas continúa más adelante recogiendo la idea de visión de mundo propuesta por Lucien Goldmann, para solucionar el problema que se plantea al intentar articular infraestructura con la superestructura, para así mostrar el momento exterior del derecho, el cual le da la uniformidad que necesita para cerrar el punto. 


\section{LA CRÍTICA A LA TEORÍA DEL DERECHO SOVIÉTICA}

El segundo aspecto que se mantiene constante en los razonamientos de Poulantzas respecto al derecho es la crítica en contra de las diversas propuestas teóricas provenientes de la Unión Soviética. Estas ideas difícilmente podríamos circunscribirlas a una tradición, a pesar de las distintas polémicas existentes entre los distintos autores, debido a que nunca existió una verdadera institucionalización de la enseñanza del derecho soviético, donde se formara a los estudiantes abordando estas polémicas. La causa de todo esto fue esencialmente que, Evgeny Pashukanis, autor de Teoría general del derecho y marxismo, debió desdecirse de parte de sus ideas esbozadas en la primera mitad de los años veinte ${ }^{8}$ y luego cayó en desgracia siendo procesado en los juicios de Moscú acusado de "formar parte del bloque de derechistas y trotskistas(!)" [sic]? Tampoco Petr Ivanovic Stucka, autor de La función revolucionaria del derecho y el estado, se pudo salvar de la derrota que sufrió una parte de los revolucionarios bolcheviques en los años veinte, porque precisamente Andrei Vishinsky, otro de los teóricos del derecho soviético, y quien además fue el fiscal de los procesos de Moscú, veló para que se le apartara de la vida pública ${ }^{10}$.

Poulantzas hizo sus críticas explícitas tanto en La teoría marxista del Estado y el derecho y el problema de la alternativa, fechado dentro del final del periodo sartriano, como en Marx y el derecho moderno del periodo cercano al estructuralismo. Categoriza a los críticos marxistas del derecho en dos grupos:

a) Uno voluntarista, cuyos exponentes son Reisner y Vyshinsky, dado que reducen las normas jurídicasestatales a meros datos-hechos, aislándolas de los valores que expresan, y;

b) otro economicista, representada por Stuchka y Pashukanis, puesto que consideran al derecho como un "sistema y orden de las relaciones sociales ratificado por el Estado" ${ }^{11}$. La crítica tiene matices, debido a que para Stuchka la correspondencia es con la subjetividad de la clase dominante, sus intereses de clase; y para Pashukanis, la correspondencia sería con las relaciones entre poseedores de mercancías.

Como corolario de esta clasificación, Poulantzas considerará tanto a Stuchka como a Pashukanis como parte de los exponentes de una teoría marxista instrumentalista del derecho, en tanto consideran a éste como un mero reflejo de la base económica. Las críticas de Poulantzas a los autores recién mencionados, se podrían esquematizar de la siguiente manera:

\footnotetext{
${ }^{8}$ ZAPATERO, Virgilio. En torno a E. B. Pashukanis. En Pashukanis, Evgeny, Teoría general del derecho y marxismo. Barcelona, Labor, 1976.

${ }^{9}$ Id.

${ }^{10}$ Id.

${ }^{11}$ POULANTZAS, Nicos. (1969). Op cit.p. 12
} 
1. Existe en estos autores un rechazo de la especificidad del sistema coherente de normas, y por tanto de la autonomía relativa del derecho y del estado respecto de la base económica. Para efectos de desmenuzar esta crítica recién enunciada, la dividiremos en dos partes:

Primero, respecto el carácter específico del sistema coherente de normas, tenemos que comprender que la coherencia en nuestros ordenamientos jurídicos no ha sido la regla, sino que es sólo una apariencia. En este sentido podemos recordar lo que planteaba el jurista chileno Eduardo Novoa Monreal frente a lo que denominaba la maraña legislativa, en su obra El derecho como obstáculo al cambio social. La pretensión de coherencia es sólo una expresión ideológica del pensamiento burgués. Dicha pretensión no es tal, dado que existen a lo menos dos paradigmas para legislar. Uno es la idea de raigambre liberal con sus ficciones y principios abstractos, y otra es la que ha sido producto de las diversas luchas sociales y que se comenzó a cristalizar en el tiempo después de la codificación. Ambas tradiciones de pensamiento del derecho se encuentran todavía enfrentadas (la liberal y la socialista), y es un conflicto que actualmente parece irresoluble. Un ejemplo de esto es la todavía vigente ficción de conocimiento de la ley (la ley se entiende conocida por todos), enfrentada a una hipertrofia legislativa que se vuelve "una verdadera trampa para el honesto ciudadano dispuesto a acatar todo aquello que la autoridad legítima pueda reclamarle" ${ }^{12}$.

Segundo, con respecto a la autonomía relativa del derecho ${ }^{13}$, podemos estimar tal como se preguntara Edward Palmer Thompson en Miseria de la Teoría, queda cuestionarse hasta qué punto existe una autonomía relativa, y de esta pregunta surge una más conflictiva: ¿existe realmente una autonomía relativa del derecho? Recordando la explicación de Thompson, podemos decir que el derecho no está ubicado en su nivel en el ordenamiento de la estructura social, sino que en todos los niveles adopta formas distintas en los distintos modos de producción y en las relaciones productivas. En palabras de Thompson:

Hallé que el derecho no se mantenía cortésmente en un "nivel", sino que estaba imbricado en cada uno de esos malditos niveles; estaba imbricado en el modo de producción y en las propias relaciones productivas (como derechos de propiedad, definiciones de prácticas agrarias) y simultáneamente estaba presente en la filosofia de Locke; se introducía bruscamente con toga y peluca bajo capa de ideología; bailaba con un cotillón con la religión, moralizando acerca del teatro de Tyburn; era un brazo de la política y la política una de sus armas; era una disciplina académica, sujeta al rigor de su propia lógica autónoma; contribuía a la definición de la propia identidad tanto de los gobernantes como de los gobernados; $y$ por encima de todo, proporcionaba un terreno para la lucha de clases, donde se dirimín nociones alternativas de la ley. ${ }^{14}$

Por tanto, el rol que desempeña el derecho en una sociedad determinada solo puede entenderse comprendiendo la pluralidad y diversidad de determinaciones históricas atendiendo al proyecto de una clase

\footnotetext{
${ }^{12}$ NOVOA MONREAL, Eduardo. El derecho como obstáculo al cambio social. México, Siglo XXI, 1983, pp. 47-55.

${ }^{13}$ El análisis más interesante, y que se caracteriza por su concritud, se encuentra en el estudio clásico de Poulantzas: Poder político y clases sociales en el estado capitalista. Mexico, Siglo XXI, 1972, pp. 364 y ss.

${ }^{14}$ THOMPSON, Edward Palmer. Miseria de la teoría. Barcelona, Crítica, 1988, p. 288.
} 
social en su momento concreto. Pashukanis, en el capítulo IV de Teoría general del derecho y marxismo se acerca más a esta posición que reconoce las determinaciones históricas, explicando lo siguiente:

La teoría marxista considera ( ... toda forma social como una forma histórica y acepta, por consiguiente, la tarea de explicar las condiciones históricas-materiales que han hecho reales esta o aquella categoría. Los presupuestos materiales de la mediación jurídica o de la mediación de los sujetos jurídicos son explicados de modo no diferente a como lo explica Marx en el primer tomo de El capital. Es cierto que Marx lo hace de pasada, a modo de indicaciones que, para la comprensión del elemento jurídico de las relaciones humanas, ayudan bastante más que la teoría general del derecho. ${ }^{15}$

La respuesta del autor me parece más útil a la hora de la concreción de un proyecto específico para la construcción de hegemonía, en el sentido de que aspira a lograr una identificación con su destinatario, más que elaborar un conocimiento abstracto.

2. La segunda crítica de Poulantzas contra el economicismo de la crítica al derecho, es que el aparato teórico de Pashukanis carece de un objeto. Para Poulantzas, siguiendo a Althusser, el derecho en tanto componente de la sociedad es parte de un todo estructurado, y por tanto, dotado de autonomía relativa, poseyendo de esta forma un objeto específico para elaborar ciencia.

Este objeto específico para el autor no se encuentra explícitamente en la obra del jurista soviético. El problema para el griego radica en que la teoría marxista no se hallaba en aquel momento por completo desarrollada, no existiendo una práctica teórica expresa que pudiese distinguirse de las demás prácticas sociales. En Pashukanis no hay práctica teórica, sólo hay crítica de las relaciones entre poseedores de mercancías, la cual está en directa relación con la práctica política de la Segunda Internacional. En este sentido, Poulantzas afirma que:

Esta concepción de Pashukanis puede ser explicada por el desconocimiento que predominó durante largo tiempo en el pensamiento marxista, a pesar de Marx y Engels, de la relación entre base y superestructura, pero también por la desconfianza que este autor, en contacto con el pensamiento occidental de su época, había concebido hacia la noción misma de la superestructura. ${ }^{16}$

La crítica expuesta por Poulantzas contra Pashukanis resulta injusta por las siguientes razones: primero, usando la expresión de Bensaid, Poulantzas se comporta como un superman teórico ${ }^{17}$, dado que critica a-históricamente al considerar que éste, al no operar con las categorías althusserianas de la ciencia marxista, las de la práctica teórica, las generalidades I (conceptos ideológicos), II (la práctica teórica) y III (conceptos científicos liberados de toda ideología), no está contribuyendo a la construcción de conocimiento específico, y finalmente de hegemonía; segundo, porque de la lectura de Teoría general del derecho y marxismo, es posible encontrar un objeto de estudio. Éste lo podemos definir de manera general como una crítica de los conceptos jurídicos, donde la teoría general del derecho:

\footnotetext{
${ }^{15}$ PASHUKANIS, Evgeny, op. cit., p. 95.

${ }^{16} \mathrm{Ibid}$, pág. 16

${ }^{17}$ BENSAID, Daniel. "Poulantzas, la politique de l'ambiguité”. Critique de l'économie politique. n 11-12, 1973.
} 
No puede tener por materia únicamente definiciones formales y convencionales y construcciones artificiales ( ... . . Ahora bien, la teoría jurídica opera con abstracciones no menos artificiales; el sujeto jurídico o la relación jurídica [las que] tampoco pueden ser estudiadas con los métodos de las ciencias naturales, pero detrás de tales abstracciones se ocultan tal vez fuerzas sociales absolutamente reales ${ }^{18}$.

Lo que encuentra detrás de esta disputa acerca del aceptar o criticar es simplemente la lucha de clases. Resulta muy distinto aceptar estas abstracciones acríticamente, que adoptarlas desde una posición opuesta a la complicidad.

\section{DERECHO E IDEOLOGÍA}

El último aspecto que me interesa abordar es el siguiente: de acuerdo a la caracterización de Poulantzas (y también de Althusser, en cuanto a que el derecho solo puede ser comprendido dentro de un todo estructurado) no hay un espacio en el cual ideología y derecho se articulen, y esta relación pueda ser explicada conforme a las nociones desarrolladas. Poulantzas vio este problema al parecer, pero su solución fue notoriamente insuficiente. En Poder político y clases sociales, propondrá que se da en una región especial, y da un ejemplo:

Esta ideología jurídico-política detenta un lugar predominante en la ideología predominante de ese modo de producción, ocupando el lugar análogo de la ideología religiosa en la ideología predominante del modo de producción feudal"19. Es necesario recordar que ésta instancia especial se encuentra determinada por la instancia económica, por el proceso de trabajo y por la producción misma. Su efecto es el "efecto de aislamiento" que afecta a los agentes de sus relaciones como relación de clase, transformándolos en sujetos jurídicos y económicos. ${ }^{20}$

Así, la escisión se da en tres planos, en el de lo jurídico, en el de la ideología político-jurídica, y en lo ideológico en general. Con este modelo explicativo Poulantzas no resuelve un problema que queda planteado, que es el cómo interactúan el derecho y la ideología en esta instancia especial, o al menos nunca dice cómo. Se limita a dar el ejemplo de la competencia en el estado capitalista: el aislamiento se da entre obreros asalariados y entre capitalistas propietarios privados, que se manifiesta en la "individualización" de esos agentes, que afecta también a las vidas económicas de éstos.

Otra solución al parecer no explorada aún en lo que respecta al derecho y su relación con la ideología, es que precisamente carece de un espacio específico. Finalmente una última posibilidad puede ser, para usar la el aparato de Althusser ${ }^{21}$, que esta relación puede darse de manera contradictoria y ser antagónica como no antagónica.

\footnotetext{
${ }^{18}$ PASHUKANIS, Evgeny, op. cit. p. 45.

${ }^{19}$ POULANTZAS, Nicos, 1972, p. 157.

${ }^{20}$ Id, p. 159.

${ }^{21}$ La caracterización de la contradicción puede encontrarse en Contradicción y sobredeterminación, artículo contenido en ALTHUSSER, Louis. La revolución teórica de Marx. Mexico, Siglo XXI, 1969.
} 
En la propuesta de niveles de escisión no se le da respuesta a las relaciones entre ellos. Desafortunadamente, en obras posteriores no dio mayores luces acerca de la articulación espacial del derecho dentro de la tópica. En Fascismo y dictadura, un texto que es ante todo militante, las referencias más cercanas a este punto dirán relación con la forma del estado y no con la forma jurídica en particular. Llama la atención que no se aborden ni siquiera someramente las transformaciones que se pudieron dar en el derecho privado en los regímenes fascistas. Tampoco lo hará en Estado, Poder y Socialismo, porque el foco de atención es distinto. La pregunta fundamental que se hace Poulantzas a propósito de este tema no es acerca del rol que ocupa el derecho espacialmente en relación con las otras instancias, sino que es acerca de la fundamentación del porqué obedecemos las normas, y qué rol juega la violencia para limitar nuestro actuar.

Otro problema visible en la obra de Poulantzas que me parece necesario considerar es la antinomia que se da en el aparato ideológico-jurídico, en el conflicto entre la autonomía relativa del derecho y la generación de normas estatales de la clase hegemónica y las clases dominantes en el Estado. La pregunta que nos surge es: ¿cómo se desenvuelve esta contradicción en la lucha de clases? Poulantzas salva el problema remitiéndose a que estas ideologías convivirían como las diversas expresiones orgánicas e inorgánicas de las clases en el sentido común ${ }^{22}$. No me parece una buena solución, pero quién sí ofrece una vía más provechosa para abordar el problema será justamente Pashukanis.

A propósito de la ideología jurídica Pashukanis y Stuchka protagonizaron el conato más interesante de la teoría del derecho socialista de principios de siglo. El debate podemos reconstruirlo releyendo los prólogos de Teoría general del derecho y marxismo y los prefacios de La función revolucionaria del derecho y del Estado. Primero, se encuentra los argumentos esbozados por Stuchka:

a) Pashukanis asimila la forma jurídica a la forma mercancía y trata de analizar al derecho con un método similar al de la economía política, tal como lo plantea Marx en El capital, "colocando en la base del análisis las generalizaciones y abstracciones elaboradas por los juristas burgueses, intenta mostrar al desnudo el condicionamiento histórico de la norma jurídica ". Concluye así que el derecho se deriva de la relación jurídica del cambio de mercancías, dejando fuera a la relación de dominio.

b) Pashukanis, a pesar de polemizar contra los ideólogos burgueses, se refiere a la "forma jurídica" como un simple reflejo de la ideología, descuidando que no es un simple reflejo y que la "ideología jurídica es reflejo del derecho en cuanto forma concreta"23

El emplazado respondió a la primera crítica que la forma jurídica es:

i. una abstracción lógica;

\footnotetext{
${ }^{22}$ POULANTZAS, Nicos, Ibid.

${ }^{23}$ STUCHKA, Peteris. La función revolucionaria del derecho y del estado. Barcelona, Península, 1969.
} 

ii. producto de una real y concreta forma mercantilizada;
iii. mediada por las relaciones de producción.

Resulta interesante esta explicación debido a que muestra cómo el derecho y la ideología tienen en realidad una relación orgánica y no a través de distintas estructuras. Podemos encontrar en esta disección de la forma jurídica, tres componentes: la mercancía, lo intercambiado o enajenado; la producción concreta de normas, dotada de una existencia real, y que pasaría a obligar; y la mediación, que por ejemplo en una relación inter pares sería el contenido de la obligación. Lo que pone de manifiesto que tanto la ideología como el derecho participan en cada uno de estos tres niveles de análisis.

A la segunda crítica se le puede oponer la argumentación del capítulo II de Teoría general del derecho y marxismo, en cuanto Pashukanis considera que el derecho solo puede entrar a determinar una realidad que ya ha sido mistificada, y donde las fantasmagorías cerebrales ya están haciéndose objetivas. Explica así que:

El Estado no es solamente una forma ideológica, sino al mismo tiempo una forma del ser social ( ... L La perfección formal de los conceptos de territorio del Estado, de población, de poder refleja no solo una ideología sino una objetiva forma de una esfera real de dominio centralizado y por tanto, la constitución sobre todo de una real organización administrativa, financiera y militar y de un correspondiente aparato humano y material. ${ }^{24}$

Para nosotros, lo que resulta destacable de Pashukanis en este aspecto, es que su punto de partida no es un a priori, no es la combinación específica que se da entre relación de propiedad y relación de apropiación real, sino que parte desde lo concreto. El derecho es una relación social, y como tal puede dar forma a otras formas sociales. Luego, continúa explicando que el derecho regula las relaciones sociales, tal como indica la relación, esto puede sonar en este momento como una proposición tautológica, pero es la forma más concreta para meterse en el problema. ${ }^{25}$ En este sentido podemos encontrar relaciones reguladas por el derecho externamente. Pero, ¿cuál es el momento en que esta relación se vuelve injusta? Conforme a esta formulación nos debiésemos introducir en el derecho privado, "donde las premisas a priori del pensamiento jurídico se revisten de la carne y de la sangre de las dos partes contendientes que defienden con la vindicta en la mano el derecho propio ${ }^{26}$. Es aquí donde se da el primer equilibrio catastrófico en el derecho. Su causa, la propiedad privada de los medios de producción.

\footnotetext{
${ }^{24}$ PASHUKANIS, Evgeny, op. cit.p. 63

${ }^{25}$ Id.p. 65

${ }^{26}$ Id.p.66
} 


\title{
CONCLUSIÓN
}

Para finalizar pienso que es necesario reflexionar acerca de cuál debe ser el contenido de lo que queremos construir como derecho, yendo más allá de las escisiones y los niveles de análisis de éste. Poulantzas tilda a la idea de justicia como ideológica, pero no se refiere en ningún momento a su base material. Resulta cuestionable la cesión de la trinchera de "la justicia" que realiza Poulantzas situándola en región ideológica jurídico-política de la ideología dominante. Es problemático negar la idea de que el derecho puede volverse una falsa representación de la realidad, siguiendo con este razonamiento, nos podemos devolver hacia una teoría instrumentalista de éste. Por tanto, resulta necesario comprender que la justicia (entendida como la idea de que los individuos deberían tener a su disposición los recursos necesarios para acceder de modo igualitario a las ventajas que les proporcionen una vida digna y que las libertades deberían estar distribuidas con equidad ${ }^{27}$ ) sí es un valor al que debemos recurrir, pero no el único. También la solidaridad, la sustentabilidad e incluso la eficiencia deben ser valores a perseguir en la sociedad de transición.

\section{MARXISM AND LAW: POULANTZAS CRITICISM ON A PASHUKANIS AND STUCHKA}

\begin{abstract}
The purpose of this paper is to consider some of the critical reflections of Nicos Poulantzas on law, in the period where his work was more influenced by the thought of Louis Althusser. For this, I will focus my analysis occupying some of the ideas raised in articles Marxist theory of state and law and the problem of alternative and Marx and modern law, in conjunction with larger works as political power and social classes in the capitalist state and Fascism and dictatorship, in which we can begin to consider that it has moved away from the core of the Althusserian project, in which the law is constitutive of the social totality, while the superstructure instance. In this analysis I will address the various criticisms made to Soviet authors as Pashukanis and Stuchka, looking for a possible answer to the light of posed by these authors in their works, in order to reveal possible limitations of raising Poulantzas, their inability to analyze a specific socio-economic formation, and finally their difficulties building hegemony.
\end{abstract}

Keywords: State; Law, Power; hegemony

\section{REFERENCIAS}

ALTHUSSER, Louis. La revolución teórica de Marx Mexico, Siglo XXI, 1969.

\footnotetext{
${ }^{27}$ Esta idea se encuentra un poco más desarrollada por: CALLINICOS, Alex.. Un manifiesto anticapitalista. Barcelona, Crítica, 2003
} 
BENSAID, Daniel. "Poulantzas, la politique de l'ambiguiteé. In : Critique de l'économie politique. n 11-12, 1973

CALLINICOS, Alex.. Un manifiesto anticapitalista. Barcelona, Crítica, 2003.

ENGISCH, Karl. La idea de concreción en el derecho. Pamplona, Ediciones Universidad de Navarra, 1968.

ENGISCH, Karl. La idea de concreción en el derecho. Pamplona, Ediciones Universidad de Navarra, 1968.

JESSOP, Bob. Nicos Poulantzas. Marxist Theory and Political Strategy. Londres, Macmillan, 1985, p. 40;.

MARTIN, James. The Poulantzas Reader. Londres, Verso, 2008.

MOTTA, Luiz Eduardo, "Direito, estado e poder: Poulantzas e o seu confronto com Kelsen”. In: Revista de Sociologia e Politica. Vol. 19. №38, pp. 7-25.

NOVOA MONREAL, Eduardo. El derecho como obstáculo al cambio social. México, Siglo XXI, 1983, pp. 47-55.

PASHUKANIS, Evgeny, Teoria general del derecho y marxismo. Barcelona, Labor, 1976.

POULANTZAS, Nicos. Nature des choses et droit: essai sur la dialectique. Paris, Librairie générale de droit et de jurisprudence, 1965 , págs. 262-263.

. Hegemonía y dominación en el Estado Moderno. Córdoba, Ediciones Pasado y Presente,1969.

Estado, podery socialismo. Traducción Fernando Claudín. .Madrid, Siglo XXI, 1979.

STUCHKA, Peteris. La función revolucionaria del derecho y del estado. Barcelona, Península, 1969.

THOMPSON, Edward Palmer. Miseria de la teoría Barcelona, Crítica, 1988, p. 288.

ZAPATERO, Virgilio. En torno a E. B. Pashukanis. En Pashukanis, Evgeny, Teoría general del derecho y marxismo. Barcelona, Labor, 1976.

Trabalho recebido e aprovado em setembro de 2014 